\title{
Misinforming, Misunderstanding, Misconceptions: What Informing Science Can Do
}

\author{
Antonio Cartelli \\ University of Cassino, Cassino (FR), Italy
}

\author{
cartan@unicas.it
}

\begin{abstract}
First of all a survey of the most relevant definitions and hypotheses concerning data, information, communication and knowledge is proposed. Main aim of this introduction is to give to the reader a reference frame for the analysis of the students' learning and for their knowledge construction works.

Soon after some wrong ideas are analyzed with respect to the above conceptual frame, i.e. with respect to didactic communication, to human knowledge construction and to individual cleverness in the use of the concepts pertaining to specific disciplinary fields.

At last some considerations on the above results are reported and some hints and suggestions for a revision of the Informing Science definition are proposed; all is done in a perspective that assigns to Informing Science a trans-disciplinary function that helps well-established disciplines like Didactics, Psycho ogy, Philosophy etc. to find new strategies for the analysis of the teaching-learning process.
\end{abstract}

Keywords : Informing Science, Data, Information, Communication, Knowledge

\section{From Data to Knowledge: A Survey}

It is well known there isn't a unique and well-established theory of information within the family of the so called information sciences and the most relevant reason for the absence of such a theory consists in the difficulty of keeping apart the different concepts of data, information, communication and knowledge and in the influence that each concept exerts on the others within the information/knowledge (i.e. didactic) communication process.

An attempt is made in what follows to characterize and analyze each concept while considering the most relevant interpretations born out until now.

\section{Data}

A definition of the term datum, with no reference to any encyclopedic definition, that seems reasonable to the author, is the following one: "any kind of sign or combination of them that is expressed in a well defined or socially accepted symbolic system (that is predisposed by an individual or a community) and that is used to represent a qualitative or quantitative aspect of a given phenomenon or event". With re-

Material published as part of these proceedings, either on-line or in print, is copyrighted by Informing Science. Permission to make digital or paper copy of part or all of these works for personal or classroom use is granted without fee provided that the copies are not made or distributed for profit or commercial advantage AND that copies 1) bear this notice in full and 2) give the full citation on the first page. It is permissible to abstract these works so long as credit is given. To copy in all other cases or to republish or to post on a server or to redistribute to lists requires specific permission from the publisher at Publisher@InformingScience.org spect to other descriptions reported on many books the above one has two main traits: a) a single datum is not necessarily made only by a qua ntity (a measure of any kind) or a true/false value (or any other value in a different logic system), b) it is the only concept in the information/knowledge communication process that is independent from the effects it has on subsequent 
situations or events, i.e. its existence and the value one can assign to it go beyond the intention of the creator and the interpretation of the reader.

In spite of the above considerations the same datum appears in the context of the knowledge/ /communication process as the less relevant concept in an hypothetical hierarchical structure involving datum, information, communication and kno wledge; Fig. 1 reports, by means of the well known Venn diagrams, the relationships the author hypothesizes among the foregoing different concepts.

It is quite obvious the above inclusions can also be equalities (i.e. the sets can be equivalent, that is: every element of each set can be an element of the other one) so that data can correspond with

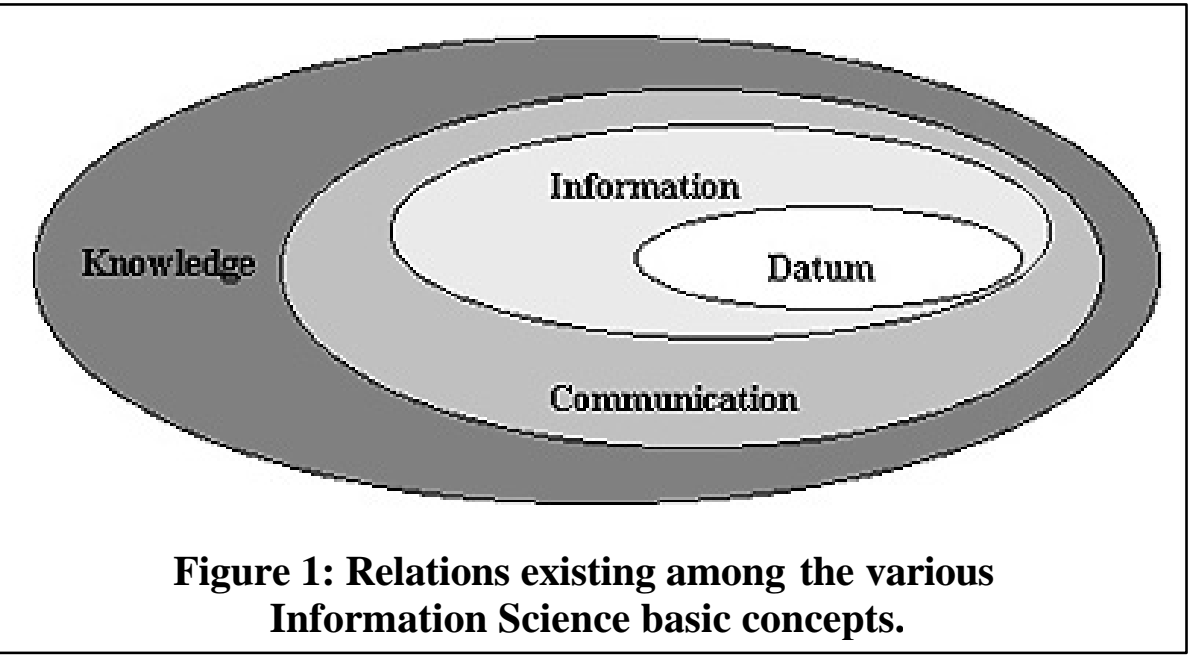
information, with communication or with knowledge and the above scheme can be used to describe those situations where the terms are used as synonyms, especially in the context of computer technology.

\section{Information}

With respect to the datum definition the literature reports a great variety of meanings for the term information. The most common approach to the information definition is the human-centered one: information, at its most basic, is data set in a context for relevance. In other words, it tells us something that is understandable and has the potential to become knowledge for us when we view it critically and add it to what we already know (Kirk, 2001).

This approach to information, while expressing its dependence from communication and knowledge emphasizes the meaning and the use of the message, i.e. "what the message is about?" and "what is already known?". In such a case many authors state that when the message is random, or it has no value for the recipient, there is no information to be received or transmitted. The above definition has another relevant feature: it puts on the same level information and meaning, but many scholars distinguish the detection and/or interpretation of information from the information itself (Stonier, 1990).

Many other definitions of information, involving at different extents psychological and sociological considerations, can be found in the literature and a good synthesis for the most relevant ones can be found in the work of R. M. Losee (1997). This author while considering the points of views of engineers, mathematicians and physicists, states the importance of quantitative aspects of information and proposes the following definition to join all the needs: "information is produced by all processes and it is the values of characteristics in the processes' output that are information". The above definition captures most part of the information's concepts in single disciplines while the number of possible values in the output and their relative frequencies of occurrence may be used in measuring the amount of present information.

At last is reported here the definition of information due to C. Lehner (2000) strongly dependent on the notion of interpretation and on semiotic considerations. This author proposes a dynamic notion of information 'holding the place between' raw data and knowledge and suggests the scheme reported in Fig. 2 to outline the model of his theory of data, information and knowledge and their interrelations. 
The arrows denote the processes respons ible for the transformation of data into information, of information into knowledge and of knowledge into data again. Raw data may be per-

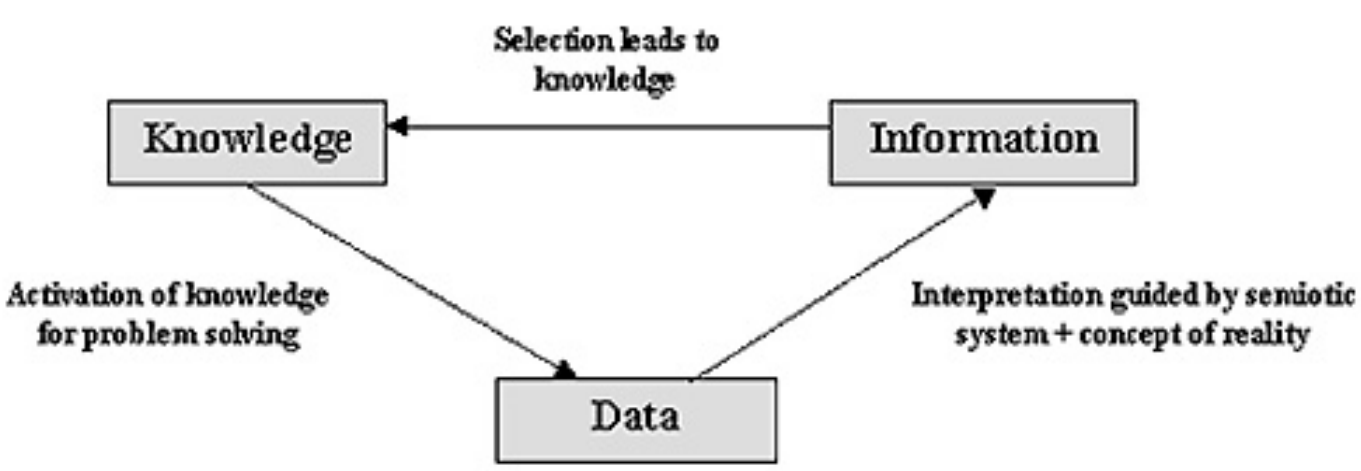

Figure 2: Representation of the C. Lehner's dynamic notion of Information. ceived through our senses and transformed into something meaningful. Information is never raw in an absolute sense, it is always produced under the influence of a conceptual system.

\section{Communication}

The reasons for the proposal of a communication's definition in this context have to be searched in the negative answer the author hypothesizes to the following question: "is there information without communication?" It is well known, in fact, the literature proposes various hypotheses for an information definition independent from human beings and from communication processes but, in the author opinion, this positivistic point of view hasn't a counterpart in the reality, where information is always contextualized. A further theoretical reference for the author's hypothesis can be found in the cognitivistic HIP (Human Information Processing) model of human mind, that compares the human knowledge processes to the computer functions: i.e. information and knowledge originate from data processed, transmitted and received from the various brain components (communication is then an essential component of the learning process).

The starting point for an analysis of the communication processes is the C. E. Shannon and W. Weaver (Shannon, 1949) theory of communication. The authors compared the information to the physic concept of entropy but centered their attention on the communication, they also proposed for that process the well known scheme that is synthesized in Fig. 3.

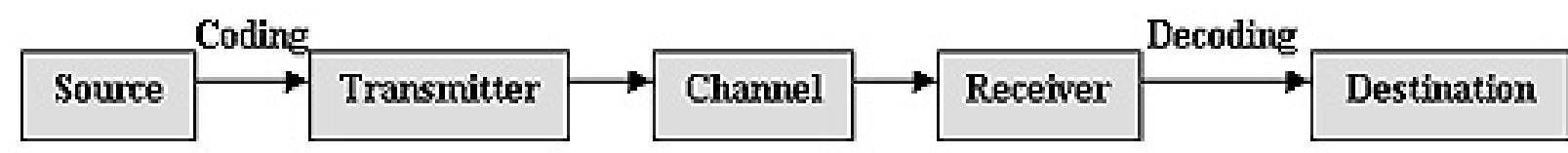

Figure 3: Model of the C. E. Shannon and W. Weaver communication scheme.

While starting from the above scheme R. M. Losee proposes a specific model of human communication that can be defined hierarchical because of its similarity with the layers' structure usually adopted in the description of the computer network's communication. The structure of this model is reported in Fig. 4 (Losee, 1997); the "U" shaped arrow within it represents the passage of something (data, information or knowledge) to be transmitted from a system/individual to another one.

In this model the definition and measure of information address the transmission of the characteristics' values from one level in the source system to the corresponding level at the destination The use of the hierarchical model allows one to focus on the level in the hierarchy that is of greatest interest, rather 


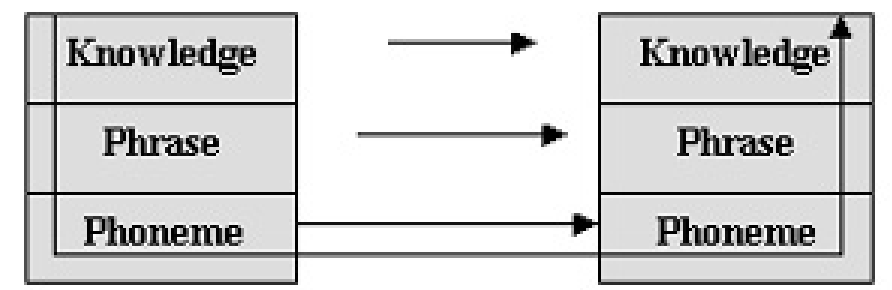

Figure 4: Model of the R. M. Losee communication scheme than getting into a debate about whether information is of one nature or another, whether it is located at one level in the hierarchy or another.

Together with engineers and technician many sociologists made great efforts to clearly and univocally define communication. The starting point for their analyses was the Shannon Weaver model but they put much attention on other differ-

ent aspects (Valli, 2000):

a) the attention to the social relevance of mass communication and to the concept of interdependence in the communication cycle as it was proposed by Osgood and Schramm;

b) the role of the culture and of the social system in the communication process and the effects of the interactions among the abilities, the social values and the aptitudes of source and receiver in the SM-C-R model of Berlo (Source-Message-Channel-Receiver);

c) the importance of factors like the selection of input data, the meaning attribution and the perception in the model of Gerbner.

At last the contribution of the Russian linguist R. Jacobson to the definition of communication has to be considered: "Communication involves six elements: an addresser, an addressee, a message sent between them, a shared code which makes that message intelligible, a 'contact' or physical medium of communication, and a 'context' to which the message refers. Each element may dominate in a particular communicative act: language from the addresser's viewpoint is 'emotive' or expressive of a state of mind; from the addressee's standpoint it is 'conative', or trying for an effect; if communication concerns the context it is 'referential'; if it is oriented to the code itself it is 'metalinguistic' and if it points to the contact itself it is 'phatic'. The 'poetic' function is dominant when the communication focuses on the message itself" (Banks, 1997).

\section{Knowledge}

This concept is perhaps the oldest one as regards to the ones reported until now; it has been studied in fact since the origins of thinking. But it is beyond the scope of this paper a detailed analysis of the different theories philosophers developed on knowledge across the centuries.

More than on generic knowledge theories the attention will now be focused on the reference frame to be used for the analysis of knowledge construction, i.e. a) what kind of concepts will be investigate and b) what paradigms will be adopted for their interpretation:

1. only scientific knowledge, i.e. concepts and ideas belonging to well structured and organized disciplinary fields, will be investigated

2. the constructivist paradigm will be adopted, because of its characteristics (Greening 2000):

- meaning is not transmitted (learning occurs as a process of adjustment of existing concepts)

- understanding is based on interaction among a complex weave of factors (i.e. the learner's goals and existing concepts, the content of the learning experience, the context in which the learning takes place, etc.)

- puzzlement motivates learning (the sense of dissatisfaction emerges from experiences that threaten existing conceptual structures) 
- social negotiation and viability are the principle forces involved in the evolution and construction of knowledge.

The author's choice has its roots in the limits that positivistic and post-positivistic paradigms highlighted while interpreting knowledge-learning phenomena, in the results of the psycho-pedagogical studies carried out during the last century and in the outcomes many research groups recently pointed out while experimenting the construction of special learning environments (often based on the use of computers and new technologies in a constructivist context). In what follows a survey of the above hypotheses will be given.

J. Piaget, first of all, hypothesized the existence of a genetic epistemology to explain the genesis of knowledge in mankind, i.e. the individual cognitive development runs parallel to the history of science and the analysis of students' ideas can be used to explain the origin of scientific concepts. Secondly, Piaget can be considered a constructivist for his theory of cognitive development stages, that is: the evolution of the individual knowledge structure, that is marked by the passage from a stage to the following one, is due to the subject-environment interaction and is based on adaptation processes that are marked by the assimilation of the new stimuli in the old scheme and by the accommodation of the old scheme into the new one (Piaget 1971, 1973).

D. P. Ausubel, on another hand, accepted and developed the idea of a knowledge construction emerging from the addition of new units to pre-existing knowledge proposed by Gagné; the same author based his theory on the following three elements: a) the internal coherence of the topic to be learned, b) the existence of a net of pre-existing concepts the new topic had to connect to; c) the subject's bent to receive and accept the new topic. He hypothesized also the distinction between a meaningful learning and a mechanical learning and based this difference on the effects that the existence of subsumers (special units of previous knowledge making easier the construction of new knowledge) could have on the addition of new elements to the pre-existing knowledge (Ausubel, 1990).

On different bases with respect to the above ones moves D. H. Jonassen (1994) who founds the project of learning environments on the following elements: a) a knowledge construction that is based on individual and social influences, b) a significant context supporting problem solving skills coming from real situations, c) the cooperation between student and teacher and among peers.

Further studies introduced the concepts of multiple intelligence, learning styles and cognitive flexibility (Gardner 1993, Mc Lellan 1996, Spiro 1990) to take into the right consideration the complexity of the cognitive phenomenon.

The importance of the context and of the social effects on the knowledge development has also been stated by many recent studies, often under the influence of Vygotskij and Leont'ev hypotheses (Varisco, 2002). The most relevant results of these studies concern two specific models of the knowledge transition from the concrete to the abstract: a) the cognitive apprenticeship, b) the expert practical thinking. The former hypothesis rediscovers the well known apprenticeship properties, i.e. modeling, coaching, scaffolding and fading, and integrates them with the following new principles: articulation, reflection and exploration. The latter one, mostly due to S. Scribner studies (1997), evidences the properties of the expert thinking in a given context with respect to the novice one; the main traits of the expert thinking involved in problem solving are: a) the use of the context's elements concerning the problem to be solved, b) the adoption of economic strategies in finding solutions and c) the use of well selected and specific knowledge units and skills in determining problem solving strategies.

The most comprehensive theory concerning the influence of social phenomena on human knowledge and learning is the E. Wenger's social learning theory (1998). The main traits of the author's theory are: a) the individual is a social being and is the focus of the learning action; b) knowledge is a specific as- 
pect of competence; c) knowledge is the expression of the participation; d) meaning is the product of learning. As a consequence E. Wenger states that a practice community is also a learning community.

Together with the above researches many other studies concerned the influence that technologies and especially computers had on human learning and knowledge. As an example for the description of the student/computer interaction in a formal learning environment are reported here the three metaphors suggested by R. Taylor: tutor, tool and tutee (Taylor, 1980); these metaphors synthesize the different approaches students have with a computer: a) an automatic system supporting or substituting (in the specific situation of auto-instruction) teachers and tutors in their work, b) an instrument to be used in everyday work, c) an hard worker executing all instructions they will submit to it.

During last decades the evolution of hardware and software induced many scholars to examine in a different perspective Taylor's metaphors to consider the results of new didactic researches (Galliani, 1999). The term tutor was used, for example, to describe the well known CAI (Computer Assisted Instruction) and CAL (Computer Assisted Learning) software, but it extended also to the ICAI (Intelligent Computer Assisted Instruction Systems) and ITS (Intelligent Tutoring Systems) systems, strongly based on the use of Artificial Intelligence results and theories. The tool metaphor, in a very similar way, was used to describe how students used general purpose software like a word processor or a whole office automation package in an educational context, but included also the analysis of more complex editors they could use to create multimedia documents or hypertexts. The case of the tutee metaphor is different from the above ones because students must have computer programming skills to get computers able in solving problems. Very important in this field was the work made by S. Papert, who invented the LOGO, a graphic programming language helping the students to instruct computers in solving simple problems. Papert is also the author of the constructionism, a pedagogical theory strongly centered on computer use; the main traits of his theory are: a) computer has to be used as a learning partner; b) computer has to promote an epistemic inversion: teaching must point to "using to learn" in spite of "learning to use"; c) teaching has to be based on problem finding and problem solving and students must use trial and error strategies in their learning etc. (Papert, 1993).

More recently many other researches concerning computer influence on teaching/learning processes were made under the influenced of the constructivist hypotheses (Varisco, 2002). A first example comes from the CTGV (Cognition \& Technology Group at Vanderbilt) that proposes the creation of anchored learning environments by means of CD-ROMs reproducing real and complex situations to be analyzed from different perspectives. Further examples are due to the CSILE (Computer Supported Intentional Learning Environments) research group directed by M. Scardamalia and C. Bereiter of the Ontario Institute for Studies in Education and to the M. C. Linn team (proposing the systematic use of the computer as a learning partner): among other things the above research groups show that the use of the computer (to simulate complex environments and situations) and the adoption of cognitive apprenticeship strategies lead the students to a meaningful learning (as it is defined by Jonassen, 1995) and are therefore more useful and fruitful than traditional teaching strategies.

The Internet added further suggestions to the above ones by means of the creation of virtual communities (Rheingold, 1994) or the construction of connective and collective intelligence (Lévy, 1996). The Net appears then as the ideal medium for learning and practice communities and for cooperative researches (Calvani, 1999) or for net-learning experiences (Biolghini, 2001); it seems also it will play a more relevant role in the future because it is an essential element of a new social and cultural system with a great learning potential (Bruckman, 2002), and it is leading to meaningful and efficient learning by means of virtual classes and learning networks of students and scholars (Hiltz and Turoff, 2002). 


\section{Misinforming, Misunderstanding, Misconceptions}

The theories and hypotheses reported in the above section have, in the author opinion, the common aspect that they are pervaded by an optimistic perspective. In other words each concept, idea or hypothesis while describing or interpreting phenomena is supported from the description of the good results of the experiments showing the effectiveness and correctness of the corresponding theories, so that it appears the most complete one if not the most pervasive one.

There is nothing wrong in the above consideration but some questions arise: 1) how much of the above results and experiences can be transferred to everyday school teaching to help students in overcoming their difficulties (as they are evidenced in the International Organizations Reports)? 2) if the use of constructivist experiences and strategies (supported or not by technologies and computer) leads to a meaningful learning how this kno wledge can be related to the mastery of the usually accepted scientific paradigms?

The need for an answer to the above questions comes also from the results of the great amount of studies on the misconceptions and the wrong ideas people show while explaining natural phenomena or while answering specific questions. These studies were carried out all over the world during last decades and involved differently aged people from pupils, to middle school, high school and university students and extended sometimes to workers, professionals and teachers.

Two main aspects clearly emerge from these studies (Cartelli 2002):

a. preconceptions, misconceptions and natural mental schemes involve all domains of human knowledge; most part of the investigated fields concern scientific knowledge like mathematics, physics, statistics, computer science, chemistry, biology, natural sciences, cosmology etc. but there is (and is still growing) a relevant number of studies investigating the wrong ideas the students show with language, literature, history and many other human sciences

b. two main approaches were adopted in the above studies: a former one, that Driver and Erickson (Driver, 1983) called ideographic or naturalistic, analysing the pupils reasoning and more generally the ideas that people show when they explain different phenomena with no dependence from scie ntific paradigms, i.e. they only evaluate the internal coherence of the people's concepts and ideas; the latter one, that the same authors defined nomothetic, involving people who already approached scientific topics (or were beginners) and evaluating the correctness of their ideas with respect to the scientifically accepted ones.

It is obviously beyond the aims of this paper the analysis of the information intentionally produced to create wrong ideas or what's worst to make propaganda, misinformation and disinformation (Kirk, 2001) so that the author will propose the analysis of misconceptions and more generally of wrong ideas with respect to the concepts of data, information, communication and knowledge.

\section{Data, Information and Wrong Ideas}

The following situations will be considered in this section: a) data and information that can lead to misunderstanding when they are interpreted; b) data and information context-depending. The consequences of data and information on human knowledge will not be analyzed.

C. Lehner (2000) reports a good example of the former situations by means of an image (left side of Fig. 5) often used in cognitive psychology to depict an ambiguous content.

It is not very important here to enter into the mechanisms that are responsible for the sensualcognitive process making the left picture more ambiguous than the two smaller images on the right hand of the figure. It is more important to concentrate on the two following questions: in the above figure what are data? What is information? It's very easy to agree with Lehner that the set of an $n \times m$ pixel-matrix or 
something equivalent are the data; very different is the situation for information because of the two interpretations one can assign to the picture on the left, information depends in fact on whether there is the intent to see the old woman or the intent to see the young woman. The data in both cases are the same, but the information isn't. The context or extra information could clarify the sense of the picture and contribute in assigning information and knowledge to it.

Very different is the case of the images reported in Fig. 6. They represent two physical situations: a) an hypothetical well crossing the earth, b) a metallic guide forcing a ball to follow a curvilinear trajectory. These images have been used together with many others to investigate students' thinking on specific physical problems (Cartelli 1984, 1985, Ruggiero 1985).
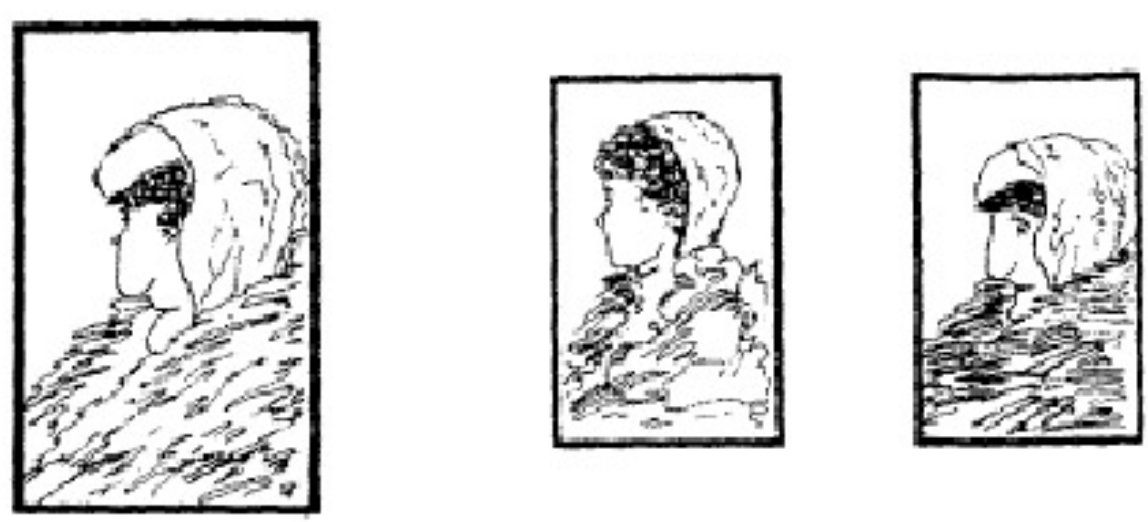

Figure 5: An ambiguous context and its possible interpretations

In the first situation the students were asked to draw the trajectory of a little stone falling in the well, in the second situation they were asked to draw the trajectory of a little ball thrown in the upper hole of the guide when exiting from the other hole (but it was also specified the guide was disposed horizontally).

If it isn't astonishing that $100 \%$ of pupils and primary school students gave wrong answers (the stone fell down and the ball described the more strange trajectories) more interesting is the case of High School and University students that gave the same wrong answers also if in different percentages (more that $65-85 \%$ depending on the students' classes). Further investigations showed in fact that among the last students, who attended specific physics courses, the ones who gave wrong answers didn't use at all the physics paradigms in the analysis of the above situations.

In this case also the context has a relevant role in interpreting information (the difference one can observe with respect to what is reported in Fig. 5 resides in the cleverness of the students in imagining or building the context to use for the assigned phenomena to correctly apply the physics laws).

\section{Communication and Wrong Ideas}

It is well known that the disjoining of information and communication in the special case of the induction of wrong ideas can be very difficult. In what follows the situations to be studied will concern only didactic communication and especially teaching situations and students' answers to specific tests. In the former case some teachers' explanations and text-books description will be considered, in the latter one 
a question concerning a well defined physic situation the students were asked to answer to will be described. The author choice derives from the hypotheses of communication's structure reported in the above section, i.e. the didactic communication process is based on a bi-directional flow of information from a source (teacher or text-book) to a destination (student) and vice versa.

With regard to the teachers there are many studies on differently aged professors (teaching in primary and secondary schools) or students attending teaching courses (MRLG 2003) that report the existence of wrong ideas (preconceptions, misconceptions and mental schemes) in physics, biology, natural sciences etc. It is quite obvious that the results of the above studies cannot be generalized but it is legitimate to hypothesize the influence of teachers' concepts on students' beliefs when solving problems or explaining phenomena.

In the case of the text-books three physics' examples that are synthesized in Fig. 7 are reported here (Cartelli 1983): a) space composition, b) speed sum, c) forces' composition in a constraint motion.

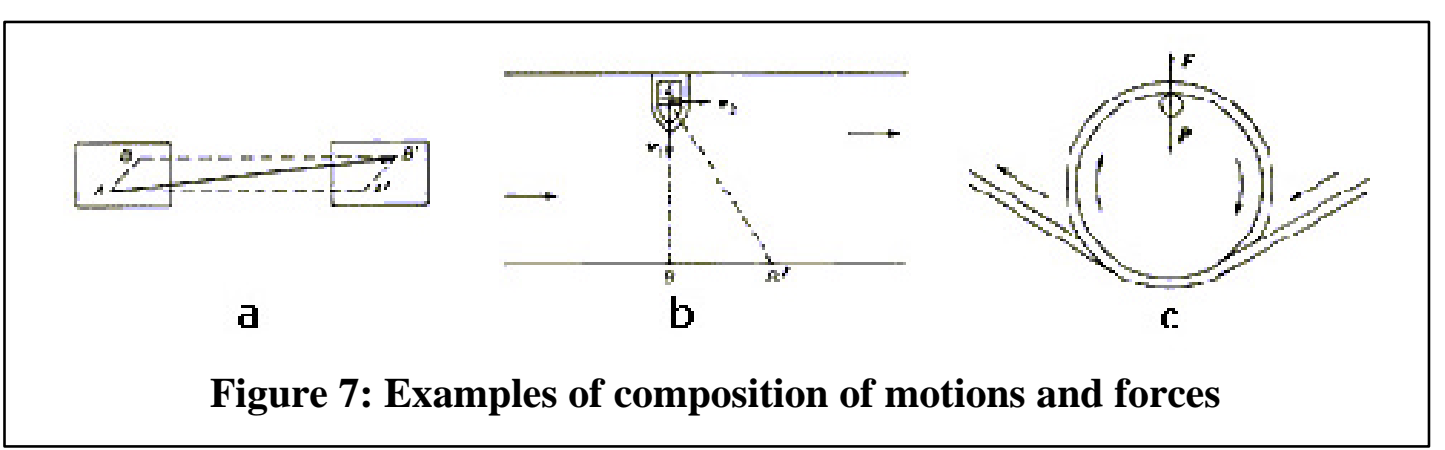

The a) situation shows a passenger going from A to $\mathrm{B}$ in a moving train wagon, the text-book explains then "at the end of the walk he/she is in B', so that it is just the same that he/she moved from A to B' as in the figure". The b) situation depicts a motorboat crossing a river (under the hypotheses of constant speeds for the boat and the water in the river), the text-book reports "when a passenger is on the boat he/she is subjected to the two speeds so that he/she is subjected to the speed that comes out from the composition of the two arrays". The c) phenomenon concerns a motorcyclist while making a death loop on the rail in the figure and the text-book explains "when at the top of the trajectory the motorcyclist is subjected to the gravity and to the centrifugal force so that he/she doesn't fall down". It has to be noted that with respect to the teachers' situation rarely appear in the physics text-books explicitly wrong explanations, but it isn't guaranteed the words "it's just the same" are right understood from the students and, what's more, the same situations are never used in the text-books to introduce Galilean relativity or to discuss with a greater detail the bodies' motion in different reference frames (that could help students in the understanding of relative motions).

As an example of students' explanation and communication the situation depicted in Fig. 8, that was used by L.

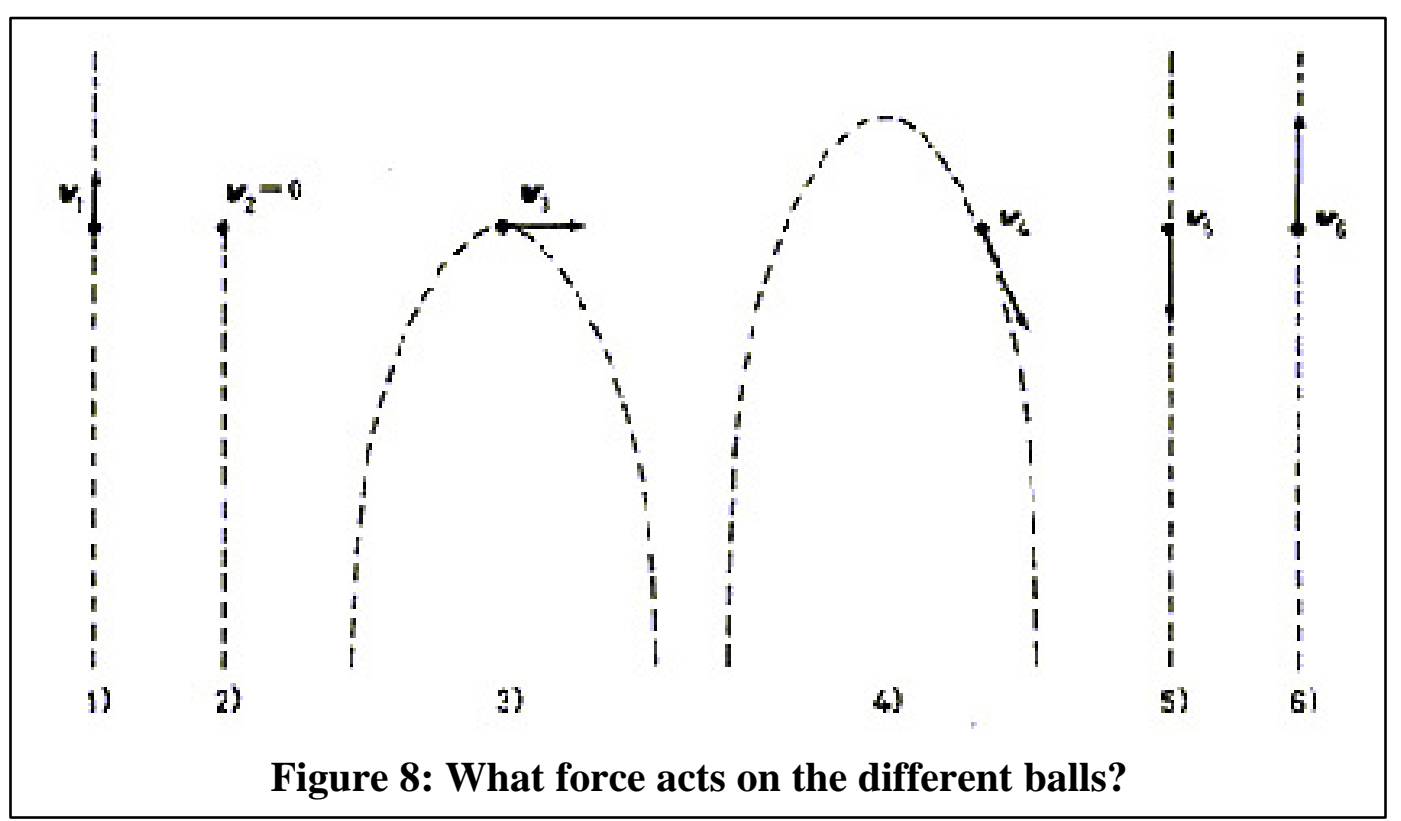


Viennot (1978) to analyze students' thinking in elementary dynamics, is reported here. The image proposes a player throwing up some balls on different trajectories and asks for the force acting on those balls when at a given instant they all are at the same height. The right answer is, obviously: there is only the gravity acting on the balls, but great part of the students (high school and university ones) see different forces acting on the various balls.

If the author's choice of the above physics' situations lies on the studies he made during his teaching experiences and it is justified from the easiness of the problems' description it has to be said that analogous situations can be found in many other fields of scientific knowledge (MLGR 2003) and sometimes in everyday newspaper pages (scientific descriptions, statistical graphics etc.).

\section{Meaningful Learning and Misconceptions}

The situation reported here concerns the students of an Italian Technical High School (16-17 aged) attending computer programming courses during school years 2000-2001 and 2001-2002 (Cartelli, 2002). The change in the field under investigation is mostly due to the new author professional interests (he was now a teacher of Computer Science and particularly Computer Programming in the High She phogl).nomenon description can be split into two parts: the former one concerns the computer programming teaching strategies adopted in everyday work and the analysis of the students' results (school year 2000-2001), the latter one reports the results of a specific test the students were asked to answer to (school year 2001-2002).

Teaching work in that class was planned having clearly in mind the results of previous studies the author held on Computer Programming misconceptions (Cartelli 1994, 1996, 1997) and was based on cognitive apprenticeship and constructivist principles that is: participated lessons; introduction to disciplinary themes strongly based on the analysis of concrete problems; modelling of expert strategies in solving problems, coaching, scaffolding and fading; articulation, reflection and exploration in the discussion of the hypotheses the students proposed for the solution of a problem; grouping of the students in small heterogeneous units (three or four individuals) for a better application of peer tutoring, etc. Special IT strategies were not used during the above teaching work because the PCs were only used into the laboratories to write and run the programs the students designed to solve problems with the Pascal, C, $\mathrm{C}++$ and Prolog languages.

At the end of the school year most part of the students were able to: recognize the range of a problem variable and choice the right type of the corresponding program variable; build algorithms with sequence, alternative and loop structures and implement them in one of the given languages; adopt modular programming and make functions and procedures implementing subprogram operations etc. In other words, as stated in former studies, at the end of the school year most part of the students overcome the problems their friend usually showed while making programs and only 6 students (24\%) among them still manifested some wrong ideas.

At the beginning of the following school year (2001-2002) after a short recovery and widening action the same students confirmed their good results so that other topics where proposed (Object Oriented Programming with $\mathrm{C}++$ and Java).

A special event occurring during this school year has had a great relevance for our study: the selections for Computer Science Olympiads; all the students of that class were in fact asked to answer to the questions of a specific test.

We will limit in what follows to the analysis of the only questions of the test concerning computer programming (i.e. variables definition and use, logic conditions within an if statement, cyclic structures, subprograms and functions). If it's true that the various items contained strongly misleading answers it 
has to be noted that only three/five students $(15 / 20 \%)$ selected the right answers, the others made the wrong choices.

The subsequent discussion the author had with the students on the answers they gave to the test easily led them to find their mistakes and to identify an explanation for their wrong answers but it doesn't change the facts: they didn't succeed in adopting the right discipline concepts and paradigms while solving the problems.

\section{Conclusions and Implications for Informing Science}

As already stated in the above section the examples the author reported until now on students wrong ideas represent only a little part (both in number of examples and in involved disciplinary field) of the amount of the studies carried out during last decades all over the world, with little or no differences in the answers that scholars and researchers obtained while passing from the North (Finland, Canada etc.) to the South (Argentina, South Africa etc.) and from the East (China) to the West (USA, Europe etc.).

The same examples show how the emersion of wrong ideas can affect the different elements in the didactic communication process, i.e. data, information, communication and knowledge. Main aspects the author reports here for their relevance are:

a. with respect to data and information, where only the context and the interpretation can intervene in modifying the value of a given concept, different elements have to be regarded when communication is analysed: the source, the code, the channel, the decoder and the receiver (in both the directions of the information flow); each one of these elements can in fact introduce elements that are responsible for the wrong ideas the students show;

b. special situations can induce the appearance of wrong ideas also after the use of special teaching strategies (strongly based on constructivism, computer technologies etc. and more generally on the experiences reported in section 1) and after having verified the right acquisition of the discipline's paradigms.

The easier explanation for the above considerations lies on the D. P. Ausubel theory of knowledge construction and on the presence or absence of subsumers helping the students in gaining a meaningful learning. Furthermore L. H. West and P. J. Fensham's suggested a revision of Ausubel hypotheses as they asserted that students can have the right subsumers to arrive to a meaningful learning, but they can reject them and give rise to misconceptions in their knowledge (West 1974).

At last the hypothesis of the "expert Vs novice paradigm", claiming the presence of an expert thinking with respect to the novice one, for the correct explanation of phenomena, hasn't proved completely correct, because "expert people" showed the same wrong ideas the students evidenced when they were asked to answer to some specific questions.

While summarizing what has been said until now on knowledge process it can be stated that natural knowledge undoubtedly emerges from the interaction among the individual and the environment and that it leads to the construction of mental schemes that work pretty well in everyday life; furthermore, just in the same way, it can be said that learning: a) occurs in context, b) is active, c) is social and d) is reflective (Driscoll, 2002). The situation seems more complex when is analyzed the interaction of scientific knowledge and natural knowledge: the hypothesis that assigns to scientific knowledge the role of a deep natural knowledge doesn't find, in fact, any confirmation in the results of the research (why people should use natural mental schemes when they have scientific ones?).

In the author opinion a more suitable model for a knowledge construction that interprets misconceptions and mental schemes presence can be hypothesised: human knowledge is the result of the superposition, not the substitution, of the scientific paradigms to the natural mental schemes. In other words, the adop- 
tion of this model states that scientific paradigms never substitute natural ones, but, what's more, they intervene in phenomena interpretation only if they are strongly impressed in the individual mental categories and practice skills (they are very similar to the seeing glasses one wears when sight problems make difficult the understanding of reality). Scientific paradigms like the glasses can help individuals in correctly looking at the reality and interpreting phenomena but, if they are not used, they can lead to phenomena misinterpretations and to the evidence of wrong ideas.

A question remains without an answer: is it possible to plan specific strategies and to design special environments (also supported by technologies) to make scientific paradigms permanent in human mind?

In the author opinion the field of investigation emerging from the above question can receive a great help from Informing Science as a discipline and especially from the use of Web Technologies in the monitoring of didactic processes and students' knowledge building (also when constructivist strategies are adopted). A research still in progress (Cartelli, 2003) is in fact evidencing the importance of the data stored in a special data base (containing all the data on the students' access to a special e-learning platform), to find a correlation among students' knowledge development and the access to the site. Some first results assign in fact a great relevance to the students' browsing stiles in knowledge construction. In other words the platform lets the researcher monitor the student's access to the site and obtain information on the didactic process and its evolution. Two monitoring strategies have been used until now: a) a former one starting from the site structure and assigning to each page the number of its visits, b) a latter one showing the chronological sequence of the pages' access of a single student.

What can be said on this investigation instrument? Before the author's proposal the most used inquiry techniques have been the tests and interviews adopted from Psychology and Sociology (Piaget used for his studies clinic interviews). Main traits of those techniques are: a) the tests are used at the beginning and at the end of the process to be analyzed, to determine what changes a given experiment induces in the individuals' mental schemes; b) the interview, with respect to the tests, is based on the interaction between two individuals (i.e. the researcher and the student) and has the disadvantage that it modifies the mental frames of the subject to be observed so that it can be very difficult to make further investigations on the same individual. In the author opinion the use of an information system like the one interfaced with a database he proposes for the e-learning environment can be a very useful inquiry instru-

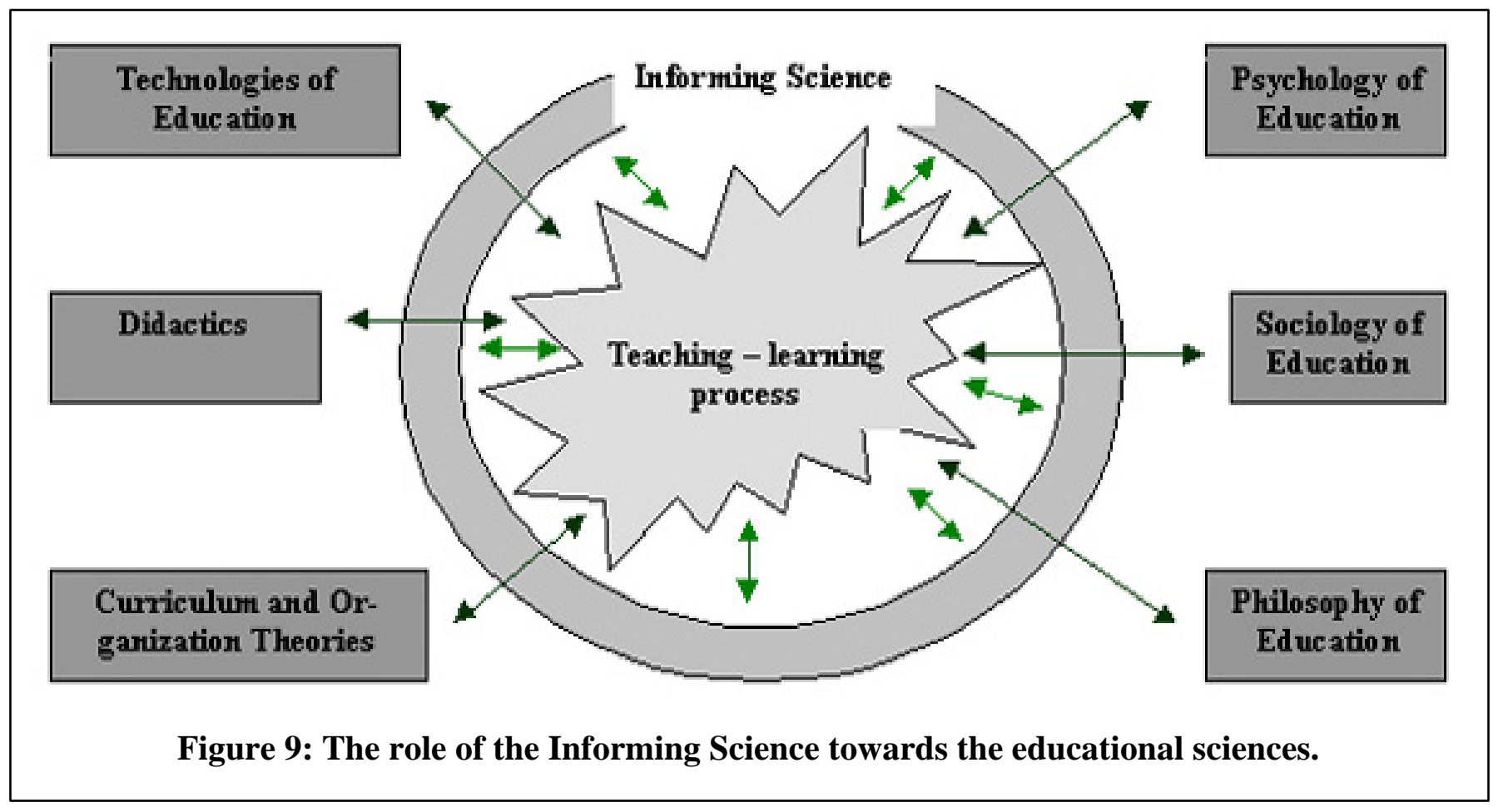


ment. With respect to the above ones it operates in fact in a transparent way (the user interacts with it like a normal Web site but every operation he/she does is stored in it) and can give at any instant a snapshot of the user interaction with the system (quantitatively: number of pages visited, amount of answers to the tests etc. and qualitatively: what pages are visited more often, what answers to the self-assessment tests are selected or written, the chronology of the interactions with the site etc.). The problem in the use of the author inquiry system is the great amount of the data it produces that needs numeric evaluation and that is, until now, very difficult to use while doing the teaching work.

The above hypotheses have relevant consequences for the disciplines involved in the analysis of the teaching-learning process and for the interactions among themselves because they assigns a special role to Informing Science as the discipline that can "provide its clientele information in a form, format and schedule that maximizes its effectiveness" (Cohen, 1999). The clients are now the disciplines usually involved in the analysis of the teaching-learning process: Technologies of education, Didactics, Curric ulum and Organization Theories, Psychology, Sociology and Philosophy, as shown in Fig. 9.

With respect to a former proposal of the same author this new one gives to Informing Science the role of an intermediary between the teaching- learning process and the disciplines that mainly study this process. Informing Science has in fact to use its languages (mostly coming from Computer Science and Statistics) but has also to acquire the elements of the languages and the methods of the disciplines it has to cooperate with.

\section{References}

Ausubel D. P., (1990). Educazione e processi cognitivi. Franco Angeli, Milan (Italy).

Banks R., (1997). Through The Valley of the Shadow. A Web Site Analysis. Available on line at http://www.georgetown.edu/bassr/511/projects/banks/final/morestruct3.htm from 04.21.1997

Biolghini D. (2001). Comunità in Rete e Net-learning. ETAS, Milan (Italy)

Bruckman A. (2002). The Future of E-Learning Communities. Communications of the ACM, XLV, 4, pp. 60-63

Calvani A., Rotta M. (1999). Comunicazione ed apprendimento in Internet, didattica costruttivistica in rete. Erickson, Trento (Italy)

Cartelli A. (1985). Mental Representation Frames in Middle School Children: Force and motion. unpublished thesis for the Special School in Physics of the University "La Sapienza" (two years post doctoral school), Rome, 22/03/1985.

Cartelli A., (1994). Misconcetti e schemi alternativi in Informatica. In (A. Andronico, G. Casadei, G. Sacerdoti ed.s) Proceedings of "DIDAMATICA 1994 - Informatica per la didattica (scientific papers)", Il Ponte Vecchio, Cesena - FO (Italy), pp. 87-102

Cartelli, A. (1996). Analisi di alcuni schemi mentali in studenti di Informatica. In (A. Andronico, G. Casadei, G. Sacerdoti ed.s) Proceedings of "DIDAMATICA 1996, Informatica per la didattica (scientific papers)", Il Ponte Vecchio, Cesena FO (Italy), pp. 64-78.

Cartelli A. (1997). Alcune indicazioni di carattere metodologico nell'insegnamento dei paradigmi di programmazione. In (A. Andronico, B. Piochi, G. Sacerdoti ed.s) Proceedings of "DIDAMATICA 1997 - Informatica per la didattica (scientific papers)", Tipografia senese, Siena (Italy), pp. 133-140

Cartelli A. (2002), Web Technologies and Sciences Epistemologies. In (E. Cohen and E. Boyd ed.) Proceedings of IS + IT Education 2002 Conference, Cork (Ireland), pp. 225-238, available on line at http://ecommerce.lebow.drexel.edu/eli/2002Proceedings/papers/Carte203Webte.pdf

Cartelli A. (2003). For a new role of Technology in education: the hypothesis of a monitoring experience, submitted for approval to the scientific committee of the revue "Document Numérique".

Cartelli A., Ruggiero S., (1983). Il ragionamento spontaneo ed i libri di fisica. Giornale di Fisica, XXIV, 3 (Jul-Sep), pp. 169186

Cartelli A., Ruggiero S., (1984). Il ragionamento spontaneo in ragazzi di terza media: il concetto di forza e gli schemi di moto. In Proceedings of the "XXIII Congresso Nazionale dell'AIF", Gaeta (LT), Italy, pp. 101-110 


\section{Misinforming, Misunderstanding, Misconceptions}

Cohen E., (1999). Reconceptualizing Information Systems as a Field of the Transdiscipline Informing Science: From Ugly Duckling to Swan. Journal of Computing and Information Technology, 7 (3), pp. 213-219, available online at http://informingscience.org/WhatsIS.htm

Driscoll M. P., (2002). How People Learn (and What Technology Might Have to Do with It), available on line in the Eric Digest Database (October 2002 / EDO-IR-2002-05)

Driver R., Erickson G., (1983). Theories in action: some theoretical and empirical issues in the study of students' conceptual frameworks in science.Studies in Sc. Educ., 10, 37

Galliani L., Costa R., Amplatz C., Varisco B. M., (1999). Le tecnologie didattiche. Pensa, Lecce (Italy)

Gardner, H. (1993). Multiple intelligences: The theory in practice. Basic Books, New York (USA)

Greening T., (2000). Computer Science Education in 21 st Century. Springer Verlag, New York (USA)

Hiltz S. R., Turoff M. (2002). What Makes Learning Networks Effective? Communications of the ACM, XLV, 4, pp. 56-59

Jonassen, D. H. (1994). Thinking Technology. Towards a Constructivist Design Model. Educational Technology, 34 (4), pp. 34-37

Jonassen, D. H. (1995). Supporting Communities of Learning with Technology: A Vision for Integrating Technology with Learning in Schools . Educational Technology, 35 (4), pp. 60-63.

Kirk E. E., (2001). Information and Its Counterfeits: Propaganda, Misinformation and Disinformation. Available on line at http://www.wealth4freedom.com/truth/information.htm from 07.20.2001

Lehner C., (2000). Information and the notion of interpretation. Available on line in PDF format at http://www.unihildesheim.de/ chlehn/artikel/dgs/info theory dgs99.pdf from 12.19.2000

Lévy P. (1996), L'intelligenza collettiva. Per un'antropologia del cyberspazio. Feltrinelli, Milan (Italy).

Losee R. M., (1997). A Discipline Independent Definition of Information. J. of the American Society for Information Science, 48 (3), pp. 254269. Available on line in HTML format at: http://www.ils.unc.edu/ losee/b5/book5.html from 03.10.1997.

Mc Lellan, H. (1996). Being digital; Implications for education. Educational Technology, November/December, pp. 5-20

MLRG (Meaningful Learning Research Group) Web site reports the titles of the papers presented at four different international meetings on misconceptions and meaningful learning: 1) Proceedings of the misconceptions in Science and Mathematics, 2) Second Misconceptions Proceedings, 3) Third Misconceptions Proceedings, 4) Proceedings of "From misconceptions to constructed understanding" Conference. The Web site is available on line on February19th 2003 at http://www.mlrg.org/

Papert S. (1993). The Children's Machine: Rethinking School in the Age of the Computer. Basic Books, New York (USA).

Piaget J., (1971). L'epistemologia genetica. Laterza, Bari (Italy).

Piaget J., (1973). La costruzione del reale nel bambino. La Nuova Italia, Florence (Italy)

Rheingold H. (1994). Comunità virtuali. Parlare, incontrarsi, vivere nel cyberspazio. Sperling \& Kupfer, Milan (Italy).

Ruggiero, S., Cartelli, A., Dupré, F., Vicentini-Missoni, M. (1985). Weight, Gravity and Air Pressure : Mental Representations by Italian Middle School Pupils. European Journal of Science Education (Eur. J. Sci. Educ.), VII (2), 181-194

Scribner S., (1997). Head and Hand: An Action Approach to Thinking. In (Tobach E. and others ed.s) Mind and Social Practice. Selected Writings of Sylvia Scribner. Cambridge University Press, Cambridge (UK)

Shannon C. E., Weaver W., (1949). The Mathematical Theory of Communication. University of Illinois Press, Urbana, Ill. (USA)

Spiro R. J., Jehng I. C. (1990). Cognitive Flexibility and Hypertext: Theory and Technology for the Nonlinear and Multid imensional Transversal of Complex Subject Matter. In (D. Nix \& R. Spiro eds.) Cognition, Education, and Multimedia: Exploring Ideas in High Technology. Lawrence Erlbaum, Hillsdale, NJ (USA), pp. 163-205

Stonier T., (1990). Information and the Internal Structure of the Universe. Springer Verlag, Berlin (Germany)

Valli B., (2000). Comunicazione e media. Carocci, Rome (Italy)

Taylor R., (1980). The Computer in the School: Tutor, Tool, Tutee. Teachers College Press, New York (USA) 
Varisco B. M., (2002). Costruttivismo socio-culturale: genesi filosofiche, sviluppi psico-pedagogici, applicazioni didattiche. Carocci, Rome (Italy)

Viennot L., (1978). Le raisonnement spontané en dynamique élémentaire. Hermann, Paris (France)

Wenger E., (1998). Communities of Practice. Learning, Meaning and Identity. Cambridge University Press, Cambridge (UK)

West L. H., Fensham P. J., (1974). Prior knowledge and the learning of science; a review of Ausubel's theory of this process, in Studies. Sc. Educ., I, pp. 61-81

\section{Biography}

Antonio Cartelli is a researcher of Didactics and Educational Technologies at the Faculty of Humanities in the University of Cassino - Italy. He has authored more than 18 papers on the subjects of Web technologies and conceptualisation, misconceptions and mental schemes in different disciplines and is administering the Network Services and the E-learning experiences that are held in the same Faculty. 